\title{
Cutting GMC investigations must not simply devolve problems elsewhere
}

\section{Tom Bourne adjunct professor and consultant gynaecologist}

Imperial College London and Queen Charlotte's and Chelsea Hospital, London, UK

The proposals outlined by Appleby in his review of General Medical Council (GMC) processes represent a real opportunity, and the GMC deserves credit for reflecting on its procedures. ${ }^{1}$ But it is important to focus beyond the GMC.

In our study on how complaints procedures affect doctors, high levels of anxiety (22\%), depression (26\%), and suicidal ideation $(15 \%)$ were reported in association with GMC investigations. However we found increased levels of psychiatric morbidity with all types of complaints procedure. ${ }^{2}$

Appleby writes, "Not everything that is needed can be brought about by the GMC alone. Employers have a crucial part to play." " This introduces a key theme of his review: reducing the number of GMC investigations and hearings, with more complaints resolved locally.

It is important to understand that all complaints investigations affect doctors' welfare. If the GMC improves procedures, it is crucial that the problem is not simply shifted elsewhere. The accountability, communication, support, and competency we hope the GMC will embrace must be mandatory wherever complaints are investigated, particularly when doctors are unwell.

Appleby's proposals represent a potential watershed for medicine in the UK. The Berwick report highlighted "fear is toxic to safety and improvement." ${ }^{4}$ If the GMC removes fear from its processes and doctors learn to trust that the GMC will act fairly, transparently, and proportionately, this will be an important step forward to "right touch" regulation. ${ }^{5}$ If this culture permeates the NHS, clinicians might feel free to speak out when things go wrong, making the NHS safer for everyone.

\section{Competing interests: None declared.}

Full response at: http://www.bmj.com/content/353/bmj.i2071/rr

1 Dyer C. GMC to cut investigations to reduce stress on doctors. BMJ 2016;353:i2071. doi: 10.1136/bmj.i2071 pmid:27067522.

2 Bourne $T$, Wynants $L$, Peters $M$, et al The impact of complaints procedures on the welfare health, and clinical practice of 7926 doctors in the UK: a cross-sectional survey. BMJ Open 2015;5:e006687. doi:10.1136/bmjopen-2014-006687 pmid:25592686.

3 General Medical Council. Putting mental health safety at the heart of the fitness to practise process. 2016. https://gmcuk.wordpress.com/2016/04/07/putting-mental-health-safety-atthe-heart-of-the-fitness-to-practise-process

4 National Advisory Group on the Safety of Patients in England. A promise to learn-a commitment to act. Improving the safety of patients in England. 2013. https://www.gov. uk/government/uploads/system/uploads/attachment_data/file/226703/Berwick_Report. pdf

5 Professional Standards Authority. Right-touch regulation. Revised. 2015. http://www. professionalstandards.org.uk/docs/default-source/publications/thought-paper/right-touchregulation-2015.pdf?sfvrsn $=10$

Published by the BMJ Publishing Group Limited. For permission to use (where not already granted under a licence) please go to http://group.bmj.com/group/rights-licensing/ permissions 